\title{
Forest Based Industry in Churachandpur District: From the Entrepreneurial Perspective
}

\section{Partakson $\mathbf{R C}^{1^{*}}$ and Tomba Singh $\mathbf{K H}^{2}$}

${ }^{1}$ Department of Ecnomics, Assam University Silchar-788 011, Assam, India

${ }^{2}$ Department of Commerce, Manipur University, Indo Myanmar Road, Canchipur, Imphal, Manipur, India

*Corresponding author: Partakson Romun Chiru, Assam University Silchar-788 011, Assam, India, Fax: 9103842270802; Tel: 03842270806; E-mail: prchiru1@gmail.com

Rec date: July 29, 2017; Acc date: September 27, 2017; Pub date: October 4, 2017

Copyright: (C) 2017 Chiru PR, et al. This is an open-access article distributed under the terms of the Creative Commons Attribution License, which permits unrestricted use, distribution, and reproduction in any medium, provided the original author and source are credited.

\begin{abstract}
Churachandpur district is one of the largest and most fertile hill districts of the state. The district has distinctive characteristics of forest based industries. The entrepreneurship gesture of capital market, accessibility and affordability of raw materials are the unique and emerging vision of industrial development. The district require fast track speeding up of industrial infrastructure and special aid to coordinate the unanimity of economic environmental problem and marketing instability overwhelmed by the ban and blockade culture in the state. The sustainability with the forest based resources (NTFP- Non-Timber Forest Products) by the rural mass was guaranteed to achieve the most important effort on alleviation of poverty. This study cover only Churachandpur district, the district entrepreneurs were stratified into three sample areas i.e., new market, Tuiboung market and Damkam market respectively. There are altogether 60 numbers of respondents, 20 each questionnaire were collected from the sample area and accordingly the research methodology was constructed with a deliberated design. With the help of purposive random sampling, the required numbers of primary data and secondary data were collected and further analysed with the help of SPSS software calculating correlation and regression, keeping income from forest based industries as dependent variable and monthly expenses on education, medical and fooding and clothing as independent variables. The result from the study shows the beauty of the local entrepreneurs' sustainability on forest based industry.
\end{abstract}

Keywords: Entrepreneurship; Forest based industry; Alleviation of poverty; Non-timber forest products

\section{Introduction}

Churachandpur district is situated in the southern part of Manipur. It has a population of 2,23,866 as per 2011 census, dominated by 15 ethnics like Zomis, Kukis and Nagas. The district has six development blocks. The town's population is made up of a number of communities including the Paite, Simte, Gangte, Zou, Hmar, Thadou, Vaiphei, Lusei, Kom Rem and Naga. These communities mainly belong to the TibetoBurman family. A significant number of Meitei and other plain communities also live in the town. Though each and every tribe can understand the different dialects, Paite is the most popular language in the district.

The forest sector in Manipur plays the important role of economy, culture and livelihood of large number of forest dependent poor and it represents a huge economic resource for the state. It has rich potential of various NTFPs, which are important sources of livelihood for the forest dependent population. The role of the forest and the local entrepreneur is inevitable for ushering the economic reformation. Interestingly, Churachandpur district market fertility seem to be outreach most part of the businessmen architecture, the prominent feature in this rural market were the businessmen imaginary calculation of economic benefit were more accurate than the other district markets. Despite the rural market showing the various structure of economic value, maximum of the opportunities are dominated of migrant entrepreneurs who are coming in from the outside of the state. Based on this crucial area all about the subject on poverty alleviation and sustainable development are to be main concerned, other prominent factors like the concept of entrepreneurship awareness is also non-existent; it needs deliberate system to foster the local entrepreneurs to make self-sustainable development. However, small part of the entrepreneurs who have participated have already address the sustainability of their livelihood, as the market volume of transition is quite convincing in recent decade and beyond.

This study is mainly focused on local entrepreneur, the local entrepreneurs and the role of forest is investable for ushering of economic reformation. However, the rural market has distinctive nature of informal and un-structural. Yet, owing to its unique challenges, given issues related to poverty and unemployment, poor infrastructure connectivity, low economic development and others are main concern. The local entrepreneurs are left with the limited option of the traditional or conventional system of business, ever since the business perspects started growing in the rural market. Today it offers major economic values and employment opportunity to the town dweller and becoming the important sustainability of their livelihood. This research in particular, identified the local entrepreneur's sustainability on forest based industries vis-à-vis their relationship with generated income and alleviation of poverty. 
Page 2 of 6

\section{Possible Options for Strengthening Forest Based Livelihood}

There is a need for collective intervention by the civil society organizations, business houses, financial institutions and the management to address various issues in NTFP management and trade. The most important intervention should be to build up the capacity and information based on primary collectors and the members of Autonomous District Council on management and trade of NTFP. At the same time priority of intervention has to be given to forest protection, quality production of NTFP, value added products instead of raw material NTFP, market promotion and market development etc.

\section{Review of Literature}

Several authors, organizations, commissions, economists and government agencies have express their view regarding the prospect of forest based industry in the state; Churachandpur district in particular has the potential for industry. Some of the reviews of the related literature with the article are as follows:

Nabaghan [1] mentions that NTFP was once monopolized by the private sector this submerge the opportunity of the tribals by paying low, erratic and arbitrary procurement and revenues loss of the state. However, reformation of forest act in 2006 giving more role of Gram Panchayat amending the arbitration on forest management is the most emerging vibrant institution to own, control and manage a majority of NTFP (69 items) for betterment of the socio-economic development. He further mention that the process of formation of apex-cooperative which to monitor exploitation and conservation of resources; Consultation of local stakeholder both the organized and un-organized sectors in various part of issue related to marketing management is major significance for strengthening the sustainability of livelihood from forest base industries in the state.

Krishnan [2] mentions that in spite industrial removal show the negative growth, softwood were more homogeneous than the other removal product. Maintaining the un-interrupted flow of forest products is the main criterion to serve the livelihood of all stakeholders. He further mention that long-term plan is required for planting trees on wasteland, encouraging farmer to grow tree on farm land, mixed captive plantation, and optimum utilization of wood resources is the immediate and wise solution for solving the present problem and sustained life of forest based industries in the state.

Shaw [3] mentions that the USDA forest service, forest inventory and analysis program serves a board segment of society by keeping a comprehensive inventory of the forest of the US he further stated that the emerging of scientifically approach on forest management with the help of FIA increasingly valuable with time.

Joseph [4] presented that forest are essential for healthy environment and vital role for fertility of soil and maintain the health of atmosphere. However, the forest industry have some negative impacts on the environment, but it should to ensure that forest industries abide strictly with principle of sustained yield management which is certified by the concerned environmental protection organization. He further mentions that government and people should genuinely involve in forest management.

\section{Objectives of the Study}

The present study aims to focus on opportunity and challenges faced by the local entrepreneurs in Churachandpur District [5]. In order to make the study not only of academic interest but also have practical utility, the present studies have the following objectives:

To find the entrepreneur economic comfort from the forest based industries as a source of livelihood.

To evaluate the relationship between the inflow of benefit and the alleviation of poverty.

\section{Hypothesis}

Null Hypothesis (H0): the income generated from the forest base industries is not the economic indicator of poverty alleviation.

\section{Basic for the Data Collection}

As it involved the heterogeneity and complexity of rural market and the difference in qualitative nature of entrepreneur, the structure questionnaire was maintained for collection of primary data and purposively segregated into three parts; part A consist of nine questions in relation to profile of Respondents, part B comprise five questions concerned with the respondents line of satisfaction of their earning, part C, 12 questions in connection with basic income and alleviation of poverty [6].

\section{Sample and Data Collection}

The study was conducted in District Head Quarter of Churachandpur, one of the important markets in the hill district of Manipur. Market itself show the various socio-economic values and incredible geographical suitability of enterprise establishment in the district, Many of the town Dwellers or migrated workers are taking risk as entrepreneur and challenge the threat and opportunity in the rural market [7]. However, the basic of rural market show dynamic and unorganized structure, for which entrepreneur require essential momentum and competence in analyzing of cost effective relationship. As per the conveniences of the time, the rural markets are stratified as: New market, Damkam market and Tuibuong market. There are altogether 60 numbers of respondents; out of the total 30 numbers of respondents are randomly selected from New Bazar entrepreneurs and 30 each from Damkam and Tuibuong market, respectively. Both primary and secondary data were collected for the purpose of study. The primary data were collected through questionnaire which was designed, pre-tested and finally administered to 60 respondents. Primary data were also collected through personal interaction, interview and discussion with the entrepreneurs and other related agencies. The secondary data were collected from important publication and report (published as well as unpublished) from various organizations and agency [8].

\section{Method of Analysis}

Initially data collected were gathered for codified and then administered by using SPSS English Version 21.0 for data analysis. The categorical distributions of the respondent's source of income generated from forest based industries and alleviation of poverty was presented in a tabular format and Mean and S.D is calculated. Finally conclusion are derived by calculating correlation coefficient and Multiple Regression analysis to predict the relationship between 
Citation: Partakson RC, Tomba Singh KH (2017) Forest Based Industry in Churachandpur District: From the Entrepreneurial Perspective. J Glob

Page 3 of 6

income and reduction of poverty from forest based industries and the other independent variables like age, educational level, medical expenditure, satisfaction level of earning of the respondents [9].

\section{Result and Conclusion}

In this stage proper care is systematically maintained, since it concerns data analysis, presentation and interpretation [10]. The data analysis and interpretation were on the research queries as well as research objectives. The presentation is divided in to four parts. The first part presented the respondents source of earning, the second part deals with poverty and its alleviation scheme, the third part focuses on hypothesis testing and the fourth part presents finding and conclusion.

\section{Data Analysis}

This stage is an attempt to analyse the primary data collected through questionnaire, the main purpose of the analysis is to fulfil the statement framed in the objectives and the hypotheses [11]. Therefore two suitable statistical tools namely Correlation and Regression were administered as follows.

\section{Partial correlation analysis}

\begin{tabular}{|c|c|c|c|}
\hline \multirow[t]{2}{*}{ Variables } & \multicolumn{2}{|c|}{ Gender } & \multirow[t]{2}{*}{ Total } \\
\hline & Male & Female & \\
\hline \multicolumn{4}{|l|}{ Age } \\
\hline Below 25 & 1 & 3 & 4 \\
\hline $25-35$ & 3 & 5 & 8 \\
\hline $35-45$ & 3 & 24 & 27 \\
\hline Above 45 & 1 & 20 & 21 \\
\hline \multicolumn{4}{|l|}{ Education } \\
\hline Illiterate & 0 & 11 & 11 \\
\hline Can only read & 0 & 4 & 4 \\
\hline Can read and write & 1 & 22 & \\
\hline Primary & 3 & 11 & 14 \\
\hline High School & 4 & 4 & 8 \\
\hline Others & 0 & 1 & 1 \\
\hline \multicolumn{4}{|l|}{ Marital status } \\
\hline Married & 2 & 1 & 3 \\
\hline Un-Married & 0 & 5 & 5 \\
\hline \multicolumn{4}{|l|}{ Type of occupation } \\
\hline Widow & 1 & 0 & 1 \\
\hline Supplier & 2 & 43 & 45 \\
\hline Itenerant & 5 & 8 & 13 \\
\hline Petty Shop Owner & 0 & 1 & \\
\hline
\end{tabular}

Table 1: Composite demographic characteristics of the respondents $(n=60)$.

Table 1 shows that, out of 60 numbers of respondents, most of the respondents that is 27 are under the age group of 35-45 in the local market, the age group of below 25 and above 45 stood the least with 1 respondent each.

It also revealed that most of the female respondents' that is 22 numbers of local female entrepreneurs can read and write and 4 numbers of male respondents have their education qualification up to high school level [12].
The maximum of the respondents with 52 numbers are under the categories of married status, only 3 numbers of respondents are unmarried and there are 5 numbers of respondents which fall under the categories of widow [13].

Since the local markets are un-organized natures, the maximum of the respondents (i.e., 45 respondents) engaged in itinerants' type of business enterprises and 1 respondent each is involved as supplier and petty shop owner, respectively. 


\begin{tabular}{|l|l|l|l|l|}
\hline Variables & Minimum & Maximum & Mean & SD \\
\hline Experience & 1 & 30 & 8.2417 & 5.7396 \\
\hline Capital Investment & 1000 & 156000 & 39223.33 & 40251.58326 \\
\hline Number of Product & 3 & 25 & 10.300 & 4.45048 \\
\hline Source: Computed from primary data. & & & \\
\hline
\end{tabular}

Table 2: Composite socio-economic nature of respondents $(n=60)$.

Table 2 revealed the entrepreneurs socio-economic profile in the market, there are altogether 60 numbers of respondents, the range of entrepreneurs occupational experience were started from the minimum of 1 year and the maximum of 30 years in the market. The initial capital of entrepreneurs to set-up the enterprises were with the minimum of Rs 1000 and 3 items and the maximum of 25 items with 156000 INR in the study area.

\begin{tabular}{|l|l|l|l|l|}
\hline Variables & Income & $\begin{array}{l}\text { Educatio } \\
\mathbf{n}\end{array}$ & Medical & $\begin{array}{l}\text { Food } \\
\text { and } \\
\text { Cloth }\end{array}$ \\
\hline Income & - & - & - & - \\
\hline Education & $\begin{array}{l}0.674 \\
(0.000)\end{array}$ & - & - & - \\
\hline Medical & $\begin{array}{l}0.251 \\
(0.062)\end{array}$ & $\begin{array}{l}0.217 \\
(0.108)\end{array}$ & - & - \\
\hline Food and Cloth & $\begin{array}{l}0.336 \\
(0.011)\end{array}$ & $\begin{array}{l}0.457 \\
(0.000)\end{array}$ & $\begin{array}{l}0.476 \\
(0.000)\end{array}$ & - \\
\hline
\end{tabular}

Source: Computed from primary data.

Table 3: Partial correlation between age, gender, education and marital status were controlled.

The above Table 3 show the relationship between monthly income, monthly expenses on education, monthly expenses on medical and monthly expenses on fooding and clothing of the respondents.

The table revealed that income have a strong positive relationship with the education $\left(\mathrm{X}^{2}=0.674, \quad \mathrm{P}=0.000\right)$, moderate positive relationship with fooding and clothing $\left(\mathrm{X}^{2}=0.336, \mathrm{P}=0.011\right)$, and a weak positive relationship with medical expenses $\left(\mathrm{X}^{2}=0.251, \mathrm{P}=0.062\right)$. Further, it reveals that the relationship between monthly expenses on education and monthly expenses on medical and fooding and clothing, respectively.

Education has a weak positive relationship with monthly medical expenses $\left(\mathrm{X}^{2}=0.217, \mathrm{P}=0.108\right)$. There is a moderate positive relationship with fooding and clothing. It can be concluded that the monthly expenses on medical show moderate positive relationship with fooding and clothing.

\section{Multiple regression analysis}

The hypotheses was also tested with multiple regression analysis to determine the relationship between the income generated from forest based industries and other independent variables like monthly expenses on education, monthly expenses on Medical and monthly expenses on fooding and clothing [14]. The below equation shows the regression equation for predicting the dependent variable from the independent variables:

$\mathrm{Y}=\mathrm{a}+\mathrm{b}_{1} \mathrm{X}_{1}+\mathrm{b}_{2} \mathrm{X}_{2}+\mathrm{b}_{3} \mathrm{X}_{3}$

Where,

$\mathrm{Y}=$ Income generated from forest based industries

$\mathrm{A}=$ constant

$b_{1}$ to $b_{3}=$ Represents co-efficient for the representative variables.

$\mathrm{X}_{1}=$ Monthly expenses on fooding and clothing

$\mathrm{X}_{2}=$ Monthly expenses on Medical

$\mathrm{X}_{3}=$ Monthly expenses on Education

\begin{tabular}{|l|l|l|l|l|}
\hline Mode I & $\mathbf{R}$ & $\mathbf{R}$ Square & $\begin{array}{l}\text { Adjusted } \\
\text { Square }\end{array}$ & $\begin{array}{l}\text { Std. Error of the } \\
\text { Estimate }\end{array}$ \\
\hline 1 & 0.748 & 0.559 & 0.535 & 5475.83 \\
\hline $\begin{array}{l}\text { Predictors: (Constant), Average Monthly expenses on fooding and clothing, } \\
\text { Average Monthly expenses on Education, Average Monthly expenses on } \\
\text { Medical. }\end{array}$ \\
\hline
\end{tabular}

Table 4: Model summary.

This model summary shows that the equation is moderately fit and described the relationship between dependent variable and independent variable significantly; the co-efficient of determination is 0.56 . Therefore, about $56 \%$ of the variation in the dependent data is explained by the independent data. The regression equation appears to be useful for making predictions since the value of $r^{2}$ is closed to 1 (Table 4). 


\begin{tabular}{|l|l|l|l|l|}
\hline Residual & 1679145127.805 & 56 & 29984734.425 & - \\
\hline Total & 380748333.333 & 59 & - & - \\
\hline $\begin{array}{l}\text { aDependent variable: Average Monthly Income. } \\
\text { Source: Pre-tested questionnaire. }\end{array}$ & & & - \\
\hline
\end{tabular}

Table 5: ANOVA ${ }^{\mathrm{a}}$ results.

The ANOVA table also shows positive and significant relationship among the variables wit $\mathrm{F}$ value of 23.660 and significant level of 0.000 .
Hence, from this table, it can be concluded that the model is valid and moderate accepted with existing variables (Table 5).

\begin{tabular}{|c|c|c|c|c|c|}
\hline \multirow[t]{2}{*}{ Model } & \multicolumn{2}{|c|}{ Unstandardized Coefficient } & \multirow[t]{2}{*}{ Std. } & \multirow[t]{2}{*}{$T$} & \multirow[t]{2}{*}{ Sig. } \\
\hline & B & Std. Error & & & \\
\hline Constant & 5267.672 & 1370.024 & & 3845 & 0 \\
\hline Avg. Fooding and clothing exp. & 0.813 & 0.112 & 0.211 & 266 & 0 \\
\hline Avg. education expenses & 0.319 & 0.654 & 0.204 & 2.018 & 0.048 \\
\hline Avg. medical exp. & -0.281 & -0.233 & -0.126 & -1.206 & 0.233 \\
\hline Dependent variable: Average In & & & & & \\
\hline
\end{tabular}

Table 6: Regression results (coefficients).

Multiple regression was used to find out whether Average monthly expenses on fooding and clothing, monthly expenses on education and monthly expenses on medical are useful predictor of income generated from forest based industries or not. Stepwise regression analysis results indicated that variation of income earn can influence the independent variable at above $56 \%\left(\mathrm{R}^{2}=0.559\right)$. Regression coefficients of the variables are shown in Table 6. Their relationship may be express as:

$\mathrm{Y}=5267.672$ to +0.813 (average monthly expenses on fooding and clothing) +0.319 (average monthly expenses on education) -0.281 (average expenses on medical).

At the Alpha $=0.05$ level of significance, the $\mathrm{p}$-value of $\mathrm{X}_{1}$, and $\mathrm{X}_{2}$ are $<0.05$, thus there exist enough evidence to conclude that Average monthly expenses on fooding and clothing and education were useful predictors of income generated from forest based industries for the local entrepreneurs. So, reject of null hypothesis is at a 5\% level of significant and accept the alternative hypothesis.

\section{Findings and Conclusion}

The study revealed that the amount of income generated from forest based industries has an impact on average monthly expenses of education, medical and fooding and clothing. A summary of correlation analysis indicated that extremely moderate positive relationship, but there was weak relationship between monthly income and monthly expenses on fooding and clothing.

A summary of regression analysis also indicated that about $56 \%$ of the variation in the dependent data is explained by the independent data. Regression analysis shows that monthly expenses on education and monthly expenses on medical were useful predictors of income generated from forest based industries but there was negative impact of monthly expense on fooding and clothing toward the income. Whereas age, gender and education level of the respondents were not a useful indicator of income earned from forest based industries. The cross tabulation table shows contrasting results between male and female entrepreneurs where most of the male participants belong to married categories whereas the female participants were either divorced or widowed or separated. Endowed with adaptable or affordable financial provisions and entrepreneurship literacy will offer suitable platform for local entrepreneurs of their sustainability and alleviation of poverty.

\section{References}

1. Nabaghan $\mathrm{O}$ Strengthening forest-based livelihood in the new governance system: example from Orisa, India.

2. Krishnan LR (2014) Forest, sources of life for forest based industries.

3. Shaw JD (2008) Benefit of a strategic national forest inventory to science and society: the USDA forest service forest inventory and analysis. iForest 1: 81-85.

4. Joseph AF (2003) The impacts of forest industries and wood utilization on the environment.

5. Adkoli NS (1988) Industrial Plantations in Karnataka. My Forest 24: 223-228.

6. Addressing poverty through mobilisation of community resources (2012). International Fund for agricultural Development.

7. Arnold M (2002) Classifying the links between forest and poverty reduction. International Forest Review 4: 231-233.

8. http://www.fao.org/home/en/www.fao.org\%3edocrep

9. Government of Manipur (2011) Economic Census of Manipur.

10. Hueiyen L (2010) Manipur losses 10 to $20 \%$ of Agricultural land in the Last Decade. Hueiyen News Service. 
Citation: Partakson RC, Tomba Singh KH (2017) Forest Based Industry in Churachandpur District: From the Entrepreneurial Perspective. J Glob Econ 5: 261. doi:10.4172/2375-4389.1000261

Page 6 of 6

11. Economic Blockade: Manipur 100 Days of Ag (2011) 13. Agrawal A, Cashore B, Hardin R, Shepherd G, Benson C, et al. (2013) NDTV Correspondent . NDTV, 8 November, Viewed on 7 March 2017.

12. Shetty M (2013) What are the differences natural resources produced in India? Economic contribution of forest. United Nations Forums on Forest.

14. Amartya S (1983) Development: Which Way Now?. Economic Journal 93 $745-762$. 